International Journal of Motor Control and Learning (IJMCL)

\title{
The Relationship Between Psychological Well-being with Creativity and Performance in Male Coaches of Iran's Football League
}

\author{
Morteza Homayounnia Firoozjah ${ }^{a *}$, Alireza Homayouni $^{b}$, Ali Noorizadeh ${ }^{c}$
}

a Ph.D. Motor Behavior, Department of Motor Behavior, University of Tehran, Tehran, Iran

${ }^{\mathrm{b}}$ Department of Psychology, Islamic Azad University, Bandargaz Branch, Bandargaz, Iran

${ }^{c}$ Ph.D. Sport Management, Department of Sport Management, University of Tehran, Tehran, Iran

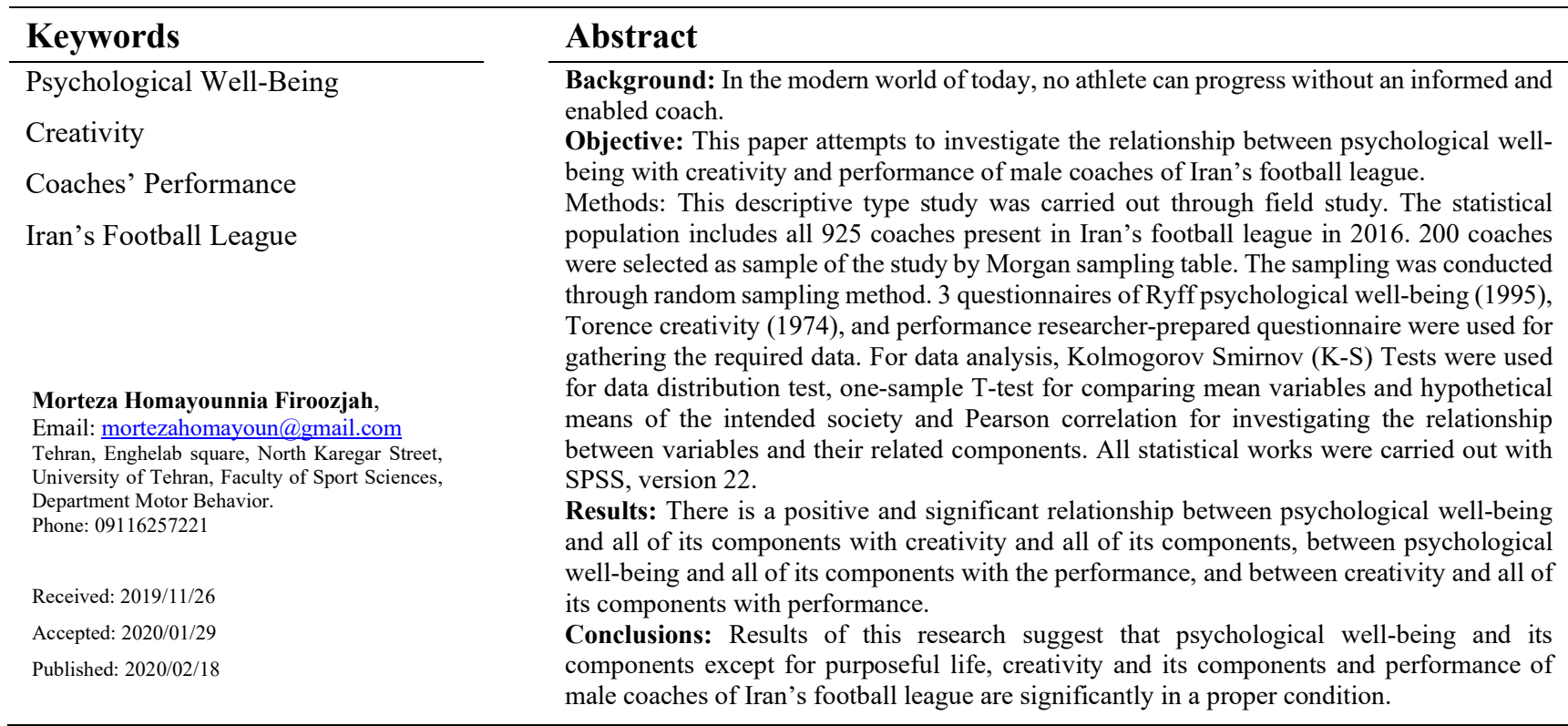

\section{Introduction}

Exercise, as a stirring activity, has a determining role in protecting human beings' physical and mental health. Based on opinion of the psychiatrists and experts of international foundation of mental health, there is a positive relationship between physical activity and mental features (Caza, Bagozzi, Woolley, Levy, \& Caza, 2010). The health issue has been topic of discussion from the genesis of human being, Middle Ages and following years; however, when the health issue is raised, only is the physical aspect simply considered. It should be mentioned that one of the important aspects of health is psychological health (Seligman, Rashid, \& Parks, 2006). One of the features that is known as influential in many of the coaches' behavioral structures is psychological well-being (Chiocchio et al., 2010).

Coaching is a considerable issue in sport psychology field. In today's modern world, no 
athlete can progress without an informed and enabled coach. Since coaches are able to have positive or negative effect on athletes' life environment, a good relationship between these two sides improves athletes' psychological skills and social well-being, and boosts their growth, selfawareness, and sense of satisfaction (Bakker \& Demerouti, 2018).

Another influential feature in coaches' success is psychological well-being. The concept of psychological well-being is applied as a general mental health term in psychology research field. Growing positive condition capacity and decreasing negative condition are defined as optimal well-being (Neves, Mesdaghinia, Eisenberger, \& Wickham, 2018). Psychological well-being is influenced by factors such as social and family relationship, individual's personality and their identity. Widom, Czaja, Kozakowski, and Chauhan (2018), in investigating the relationship between mental health and psychological health, concluded that increasing mental health causes growth of psychological well-being. Psychological well-being requires understanding of life's inherent challenges. Its approaches investigate observed growth and changes in life's inherent challenges and strongly emphasize human being's development (Widom et al., 2018). The sense of well-being has both emotional and cognitive components (Gross et al., 2018). Seligman et al. (2006) emphasized on mental well-being and considered it as having an optimistic thinking in life. He believed that emerging the sense of mental well-being would lead to emerging optimism in life which is influenced by the sense of dominance and authority (creativity) (Clement et al., 2015; Wong, Ho, Wang, \& Miller, 2017) .

Another effective factor in coaches' success is creativity. In psychological definition of creativity, the emphasis is on development of new and right view, emotion, and behavior. In these definitions, the objectives are boosting of human being's thought, personality, and their inner growth and excellence (Balk et al., 2018; Bentzen, Lemyre, \& Kenttä, 2017; Kossek et al., 2018). One of the significant features of those having psychological health is their creation and acceptable performance (Manganelli, Thibault-Landry, Forest, \& Carpentier, 2018). This type of creativity is a kind of inner growth and development which causes moving toward excellence and flourishing. In fact, generation and inner movement cause these people to enjoy the higher power of leadership and balance in mind and personality and, therefore, achieve a better balance with the subjective and objective world.

Football has attracted many fans in Iran in recent years. In sport, coaches are one of the influential and major factors regarding athletes' success. On the other hand, as psychological wellbeing and creativity in training and exercise of athletes and performance of coaches improves, there would be positive impact on athletes' performance and feedback, and would lead to their success, and improvement of their sport field dimension. Hence, considering the significance of psychological well-being in creativity and performance of coaches, this study aims at 
investigating and answering this question: Is there a relationship between psychological well-being with creativity and performance of male coaches of football league of Iran?

\section{Method}

The present study is practical in terms of purpose and correlational in terms of strategy. It is conducted through field works. Also, in gathering data related to the theoretical foundation and research literature, library studies are applied. The statistical population of this paper includes all 925 male coaches of football league of Iran in 2016. Considering the high number of the intended statistical population, random sampling method was applied, and 200ones were selected according to Morgan sampling selection table for participating in the intended tests. Three questionnaires were distributed among the selected subjects.

For gathering required data, three questionnaires, including psychological wellbeing, Torence creativity and performance one was used.

\section{Psychological Well-Being Scales}

Carol Ryff has conceptualized psychological well-being as consisting of 6 dimensions: autonomy, environmental mastery, personal growth, positive relations with others, purpose in life and self-acceptance. She has designed selfreport scales to assess individual's well-being at a particular moment in time within each of these six dimensions. Three- to 12 - items, per scale validated versions, exist of the measure for use in survey research or other data collection. Individuals respond to various statements and indicate on a 6point Likert scale how true each statement is of them. Higher scores on each scale indicate better well-being on that dimension (Ryff \& Keyes, 1995). In Iran report the validity and reliability of questionnaires the subscales of Self-acceptance, Positive Relation with Others, Autonomy, Environmental Mastery, Purpose in Life, and Personal Growth were found to be $0.71,0.77,0.78$, $0.77,0.70$, and 0.78 respectively, which were statistically significant (Bayani, Mohammad Koochekya, \& Bayani, 2008).

\section{Torence Creativity}

Paul Torrance, "Father of Creativeity," is best known for developing the Torrance Tests of Creative Thinking (TTCT). The TTCT was developed by Torrance in 1966 (Torrance, 1966). It has been renormed 4 times in 1974, 1984, 1990, and 1998. There are 2 forms (A and B) of the TTCT-Verbal and 2 forms (A and B) of the TTCTFigural. However, in the scope of this review, only the TTCT-Figural was examined. The TTCT has been translated into more than 35 languages. It has become highly recommended in the educational field and is even used in the corporate world. It is the most widely used test of creativity and is the most referenced of all creativity tests (Kim, 2006). Basic information is pre- sented, including purposes, content area, norms, reli- ability, and validity. Strengths and weaknesses of the TTCT, including use of the TTCT in identifying gifted 
learners and suggestions for further development and improvement, are provided and discussed. In Iran report the validity and reliability of questionnaires the were found to be 0.83 . Also, alfa kronbach was reported to be 0.81 (Jafarkhani, 2017).

\section{Performance}

The questionnaire underwent a variety of developmental stages. Rushall and Wiznuk (1985) ,in its final form, contained 36 items. The tool was shown to be a valid, reliable, and standardized questionnaire. It demonstrated discriminability and provoked honest and accurate responding in subjects. The test was capable of providing immediate feedback to coaches seeking information about athletes' perceptions of their coaching performance. Responses on the developed scale were weighted to reflect the desirability of the coaching characteristics of a good coach. The questionnaire provides a total score which can be interpreted by the coach as a measure of how much of an "ideal" coach exists in him/her. In Iran report the validity and reliability of questionnaires the were found to be 0.78.Also alfa kronbach reported 0.79 (Ramezaninejad, Rezai Soufi, KHOSRAVI, \& Mallaie, 2013).
For data analysis, Kolmogorov Smirnov (K-S) Tests were used for data distribution test, onesample T-test for comparing mean variables and hypothetical means of the intended society and Pearson correlation for investigating the relationship between variables and their related components. All stages were performed at a significant level of 0.5. All statistical works were carried out with SPSS, version 22.

\section{Results}

Descriptive results indicate that $48 \%$ of the subjects were single and 52\% were married. Also, it was observed that the higher number of the participants of the study were coaches with diploma degree in education which accounted for 26\%; while coaches with $\mathrm{PhD}$ included just 5\%. The highest frequency was related to the age group of 31-40-year-old with the frequency percentage of $36.5 \%$. Since the data distribution of psychological well-being and its components was normal, one sample T-test was used for investigating the research hypothesis (male coaches of Iran's football league are in a good condition in terms of psychological well-being and its components). The results are brought in Table (1).

Table (1): One Sample T-test.

\begin{tabular}{|c|c|c|c|c|c|}
\hline Variables/statistic & Mean & Statistical Mean & Degree of Freedom & $\mathrm{t}$ & Sig. Level \\
\hline Self-acceptance & 3.25 & 3 & 199 & 7.17 & 0.01 \\
\hline $\begin{array}{l}\text { Positive Inter- } \\
\text { personal } \\
\text { Relationship }\end{array}$ & 3.18 & 3 & 199 & 5.48 & 0.01 \\
\hline Autonomy & 3.1 & 3 & 199 & 2.66 & 0.01 \\
\hline $\begin{array}{c}\text { Dominance on } \\
\text { Environment }\end{array}$ & 3.09 & 3 & 199 & 2.57 & 0.01 \\
\hline Purposeful Life & 3.04 & 3 & 199 & 1.15 & 0.01 \\
\hline Personal Growth & 3.17 & 3 & 199 & 4.58 & 0.01 \\
\hline $\begin{array}{l}\text { Psychological Well- } \\
\text { being }\end{array}$ & 3.15 & 3 & 199 & 4.24 & 0.01 \\
\hline
\end{tabular}




\section{Considering}

results (1), psychological well-being and its component were significantly in a good condition psychological well-being components, just among Iran's male coaches $(\mathrm{p}<0.05)$. Among good state.

Table (2): One Sample T-test.

\begin{tabular}{cccccc}
\hline & Mean & Statistical mean & $\begin{array}{c}\text { Degree of } \\
\text { freedom }\end{array}$ & T & Sig. level \\
\hline Consciousness & 3.08 & 3 & 199 & 2.14 & 0.01 \\
\hline $\begin{array}{c}\text { Mental } \\
\text { Flexibility }\end{array}$ & 3.21 & 3 & 199 & 4.74 & 0.01 \\
\hline $\begin{array}{c}\text { Mental } \\
\text { Innovation }\end{array}$ & 3.11 & 3 & 199 & 2.26 & 0.01 \\
\hline Creativity & 3.14 & 3 & 199 & 3.28 & 0.01 \\
\hline
\end{tabular}

As it is shown in table 4, creativity and its components were significantly in a good condition among Iran's football male coaches $(p<0.05)$.

Considering that data of performance was normally distributed, one sample T-test was used shown in Table (3). for investigating research hypothesis (the performance of male coaches of Iran's football league was in a good condition. Results are

Table (3): One Sample T-test.

\begin{tabular}{llllll}
\hline Variable/statistic & Mean & Statistical means & $\begin{array}{l}\text { Degree of } \\
\text { freedom }\end{array}$ & T & p value \\
\hline performance & 3.62 & 3 & 199 & 15.38 & 0.01 \\
\hline
\end{tabular}

In table 3, performance of male coaches of Iran's football league was significantly in a good condition $(\mathrm{p}<0.05)$.

Since the variables' distribution is normal, Pearson correlation test was used for examining the relationship between psychological well-being and its components with the male coaches' creativity. The results are given in Table (3).
Since the variables' distribution is normal, Pearson correlation test is used for finding the relationship between creativity and its components with the male coaches' performance. The results are given in Table (4).

Table (4): Pearson correlation test results.

\begin{tabular}{ccccc}
\hline & Consciousness & Mental flexibility & Mental innovation & creativity \\
\hline performance & 0.38 & 0.35 & 0.34 & 0.39 \\
\hline Sig. level & 0.01 & 0.01 & 0.01 & 0.01 \\
\hline
\end{tabular}




\section{Discussion and Conclusion}

Results showed that psychological well-being and its components were significantly in a good condition among male coaches of Iran's football league. In addition, it was found that, only purposeful life, among psychological well-being components, is not significantly in a good condition. In fact, present study implies the challenges that male coaches of Iran's football league would likely encounter. Results are indicative of good condition of Iran's male football coaches for psychological variable, which is promising, and can increase their success probability in coaching. It should be mentioned that purposeful life component was not significantly in a good condition, and some reforms should be applied. Human being's performance in an organization is reflective of his/her knowledge, skill, behavior, and moral values (Karam, Gardner, Gullifor, Tribble, \& Li, 2017).

The achieved results of the present study are indicative of a positive and significant relationship among psychological well-being factors and all creativity factors. These results are compatible with those Clement et al. (2015); Wright and Klotz (2017) and Gross et al. (2018) results. Wright TA (2017) concluded that those teachers who have higher psychological well-being would have students that are more creative. Also, Wright TA (2017) suggested that by stimulating and reinforcing of creativity, one can help achieve psychological health promotion. On the other hand, research results show that psychological wellbeing has a positive relationship with academic performance, advancement for achieving personal objectives, better health, increasing job satisfaction, and decreasing job absence(Seligman et al., 2006). Therefore, the achieved results are indicative of a positive and significant relationship between psychological well-being and creativity which seems reasonable. The test results suggested that there is a positive and significant relationship between psychological well-being and its components with the performance of male coaches. This result was in line with those of Neves et al. (2018) and Wong et al. (2017). Neves et al. (2018) stated that there is a positive and significant relationship between creativity and psychological health of coaches and their performance level. Also, Peterson and Park (2006)\& Gross et al. (2018) concluded that by enhancing psychological well-being level, improvement is observed in the general health level. From this point, it could be inferred that psychological well-being has a positive relationship with the performance, since it is very clear that general health can have a positive relationship with the performance. In Ryff et al's psychological well-being model, the selfacceptance component means to have a positive attitude toward oneself and his/her past. If one is satisfied with his/her evaluation, talents, abilities and activities, in general, and feels satisfied toward his/her past, s/he would have desirable psychological functions. Results showed that there is a significant relationship between creativity and its components and the performance of the male coaches, which is in line with Gross et al. (2018), Harris, Jennings, Katz, Abenavoli, and Greenberg 
(2016), Widom et al. (2018), Manganelli et al. (2018) Bakker and Demerouti (2018) suggested that there is a positive and significant relationship between creativity and psychological health of male coaches with their performance level. In fact, in can be inferred that psychological health improvement, self-efficacy, and people's method of adaptation can be associated with their performance. Also, in sport field, the creativity and creative thinking issues are considered for all sport agents including athletes, coaches, administers, etc. because it is clear for that, most probably, creative people have higher chances for success. Today, creativity is recognized as the secret of survival and key to people and organizations' success. Coaches and sport teams, with creative minds and thinking, are no exception. By showing their innovation and creativity, they can provide the causes of their performance improvement and success. Regarding the results obtained, it can be said that selecting and choosing people with higher mental health can increase the efficiency of the coaches and, ultimately, increase the overall efficiency of the teams.

The limitation of this study was that there are very few scientific resources in this field that directly relate to the subject of study and research. Despite the great efforts of the researcher, he did not succeed in finding a research that directly addressed this issue. In addition, lack of funds necessary to carry out the work can be pointed out.

It is suggested that using psychological services in order to help increase creativity and its following, improves the performance of coaches.
In fact, using scientific workshops for trainers, increases the level of use of psychological factors in order to improve their creativity and performance.

\section{References}

1. Bakker, A., \& Demerouti, E. (2018). Multiple levels in job demands-resources theory: Implications for employee well-being and performance. Handbook of well-being. Salt Lake City, UT: DEF Publishers. DOI: nobascholar. com.

2. Balk, Y. A., De Jonge, J., Oerlemans, W. G., Geurts, S. A., Fletcher, D., \& Dormann, C. (2018). Balancing demands and resources in sport: Adaptation and validation of the Demand-Induced Strain Compensation Questionnaire for use in sport. Journal of sports science \& medicine, 17(2), 237.

3. Bayani, A. A., Mohammad Koochekya, A., \& Bayani, A. (2008). Reliability and Validity of Ryff's Psychological Well-being Scales. Iranian Journal of Psychiatry and Clinical Psychology, 14(2), 146-151.

4. Bentzen, M., Lemyre, N., \& Kenttä, G. (2017). A comparison of high-performance football coaches experiencing high-versus low-burnout symptoms across a season of play: Quality of motivation and recovery matters. International Sport Coaching Journal, 4(2), 133-146.

5. Caza, A., Bagozzi, R., Woolley, L., Levy, L., \& Caza, B. (2010). Psychological capital and authentic leadership: Measurement, gender, and cultural extension. AsiaPacific Journal of Business Administration, 2 (1), 53-70. doihttp. Journal of Organizational Change Management, 17(2), 194210.

6. Chiocchio, F., Beaulieu, G., Boudrias, J.-S., Rousseau, V., Aubé, C., \& Morin, E. M. (2010). The Project Involvement Index, psychological distress, and psychological well-being: Comparing workers from projectized and non-projectized organizations. International Journal of Project Management, 28(3), 201-211.

7. Clement, S., Schauman, O., Graham, T., Maggioni, F., Evans-Lacko, S., Bezborodovs, N., . . . Thornicroft, G. (2015). What is the impact of mental health-related stigma on help-seeking? A systematic review of quantitative and qualitative studies. Psychological medicine, 45(1), 11-27.

8. Gross, M., Moore, Z. E., Gardner, F. L., Wolanin, A. T., Pess, R., \& Marks, D. R. (2018). An empirical examination comparing the Mindfulness-AcceptanceCommitment approach and Psychological Skills Training for the mental health and sport performance of female student athletes. International Journal of Sport and Exercise Psychology, 16(4), 431-451.

9. Harris, A. R., Jennings, P. A., Katz, D. A., Abenavoli, R. M., \& Greenberg, M. T. (2016). Promoting stress management and wellbeing in educators: Feasibility and 
efficacy of a school-based yoga and mindfulness intervention. Mindfulness, 7(1), 143-154.

10. Jafarkhani, F. (2017). Investigating the Effects of Training on Reliability of Creativity Tests. Scientific Journal Management System, 7(1), 1-16.

11. Karam, E. P., Gardner, W. L., Gullifor, D. P., Tribble, L. L., \& Li, M. (2017). Authentic leadership and highperformance human resource practices: implications for work engagement Research in personnel and human resources management (pp. 103-153): Emerald Publishing Limited.

12. Kim, K. H. (2006). Can we trust creativity tests? A review of the Torrance Tests of Creative Thinking (TTCT). Creativity research journal, 18(1), 3-14.

13. Kossek, E. E., Petty, R. J., Bodner, T. E., Perrigino, M. B., Hammer, L. B., Yragui, N. L., \& Michel, J. S. (2018). Lasting Impression: Transformational Leadership and Family Supportive Supervision as Resources for WellBeing and Performance. Occupational Health Science, 2(1), 1-24.

14. Manganelli, L., Thibault-Landry, A., Forest, J., \& Carpentier, J. (2018). Self-Determination Theory Can Help You Generate Performance and Well-Being in the Workplace: A Review of the Literature. Advances in Developing Human Resources, 20(2), 227-240.

15. Neves, P., Mesdaghinia, S., Eisenberger, R., \& Wickham, R. E. (2018). Timesizing Proximity and Perceived Organizational Support: Contributions to Employee Well-being and Extra-role Performance. Journal of Change Management, 18(1), 70-90.

16. Peterson, C., \& Park, N. (2006). Character strengths in organizations. Journal of Organizational Behavior: The International Journal of Industrial, Occupational and Organizational Psychology and Behavior, 27(8), 11491154.

17. Ramezaninejad, R., Rezai Soufi, M., KHOSRAVI, A., \& Mallaie, M. (2013). The Comparison of Performance Evaluation Indicators of Club Coaches from Experts, Athletes and Coaches' Viewpoints. Journal of Sport Management, $\quad 5(2), \quad 191-214$. doi:10.22059/jsm.2013.32174

18. Rushall, B. S., \& Wiznuk, K. (1985). Athletes' assessment of the coach--the coach evaluation questionnaire. Can J Appl Sport Sci, 10(3), 157-161.

19. Ryff, C. D., \& Keyes, C. L. M. (1995). The structure of psychological well-being revisited. Journal of personality and social psychology, 69(4), 719.

20. Seligman, M. E., Rashid, T., \& Parks, A. C. (2006). Positive psychotherapy. American psychologist, 61(8), 774.

21. Torrance, E. P. (1966). Thinking creatively with pictures: Figural booklet: Scholastic Testing Service.

22. Widom, C. S., Czaja, S. J., Kozakowski, S. S., \& Chauhan, P. (2018). Does adult attachment style mediate the relationship between childhood maltreatment and mental and physical health outcomes? Child abuse \& neglect, 76, 533-545.

23. Wong, Y. J., Ho, M.-H. R., Wang, S.-Y., \& Miller, I. (2017). Meta-analyses of the relationship between conformity to masculine norms and mental health-related outcomes. Journal of counseling psychology, 64(1), 80.
24. Wright, T. A., \& Klotz, D. (2017). Character, personality, and psychological wellbeing. The Routledge companion to wellbeing at work, 85-99. 